\title{
IMAGINARIO Y REPRESENTACIONES SOCIALES SOBRE LA MIGRACIÓN Y LA IMPORTANCIA DE SU INCLUSIÓN A LA EDUCACIÓN
}

\section{IMAGINARY AND SOCIAL REPRESENTATIONS ABOUT MIGRATION AND THE IMPORTANCE OF ITS INCLUSION IN EDUCATION}

\author{
José Orlando García Mendoza ${ }^{1}$ \\ Carol Mildred Estupiñán² \\ William Rodrigo Avendaño Castro ${ }^{3}$
}

\section{RESUMEN}

El objetivo de este estudio es comprender los imaginarios y representaciones sociales de padres/representantes inmigrantes radicados en la Ciudad de Cúcuta, Norte de Santander,

\footnotetext{
$1 \quad$ Magister en Administración de empresas con Especialidad en Gestión Integrada de la Calidad, Seguridad y Medio Ambiente, Docente investigador de la Universidad Francisco de Paula Santander , Correo electrónico: orlandogarcia@ufps.edu.co Orcid: 0000-0003-4368-3975 2 Estudiante de Administración de Empresas, Universidad Francisco de Paula Santander, Estudiante investigador adscrito al Semillero de Investigación en Innovación y Gestión de Procesos-SIINGEP- UFPS , Correo electrónico, carolmildredea@ufps.edu.co,_Orcid: 0000-0001-6469-6826

3 Doctor en Ciencias Sociales y Humanas, Pontificia Universidad Javeriana. Docente investigador de la Universidad Francisco de Paula Santander. Correo electrónico: williamavendano@ufps.edu.co. Orcid: 00000002-7510-8222
}

Colombia, sobre el fenómeno de migración y educación. Los resultados apuntan a que las representaciones sociales varían con respecto a la educación en cuanto al acceso, la adaptación e integración, son una imágenes que los sujetos informantes desarrollaron en interacción con el contexto educativo de la Ciudad de Cúcuta. En conclusión, los inmigrantes al integrarse activamente a la sociedad local, organiza y regula las experiencias y comportamiento asignando un valor al contexto educativo donde se desenvuelve su representado, y a su vez, fortalece la imagen de su propia conciencia objetiva de los criterios culturales, normativos y educativo de la representación y que es anclada al sistema de pensamiento preexistente. 
PALABRAS CLAVE: imaginario, representaciones sociales, migración, educación.

\section{ABSTRACT}

Objective: to understand the imaginary and social representations of immigrant parents / representatives living in the City of Cúcuta, Norte de Santander, Colombia, on the phenomenon of migration and education. Method: Qualitative, phenomenological in nature. The key informants are some Venezuelan emigrants. To collect the information, narrative methods and life stories will be combined as it is part of the meaning of what they have had to live. Also, techniques such as the in-depth interview are used. Results: the social representations vary with respect to education in terms of access, adaptation and integration, they are images that the informant subjects developed in interaction with the educational context of the City of Cúcuta. Conclusion: immigrants, by actively integrating into local society, organize and regulate experiences and behavior, assigning a value to the educational context where their representative develops, and in turn, strengthens the image of their own objective awareness of cultural, normative and cultural criteria. educational representation and that is anchored to the preexisting system of thought.

KEYWORDS: imaginary, social representations, migration, education.

\section{INTRODUCCIÓN}

La migración de humanos por múltiples razones es compleja y complicada. La misma es una aspiración de decoro, vergüenza, dignidad, seguridad y un mejor futuro para los individuos, y es parte de la estructura social. Es parte de la familia humana a lo largo de su historia evolutiva que abarca todo movimiento de personas hacia otros territorios sea cual fuere su tamaño, su composición o sus causas; incluye migración de refugiados, personas desplazadas, personas desarraigadas, migrantes económicos (Organización Internacional para las Migraciones, 2006), pero también, la migración y el desplazamiento causan desacuerdos dentro y entre países y las mismas sociedades.

En el caso particular de la migración e intempestiva movilidad intrarregional de venezolanos según Pineda y Ávila (2019), Colombia tuvo que solicitar ayuda económica para atender esta población, Perú se declaró en estado de emergencia sanitaria en la frontera y Brasil moviliza sus tropas. Es necesario destacar, que la situación migratoria que caracteriza a Venezuela y Colombia es concomitante, así como en el pasado una cantidad considerable de colombianos emigraron a dicho país vecino, para diciembre de 2017, se calculaba en 550.000 personas venezolanas, por ello, según Aliaga et al., (2018) la migración venezolana en Colombia plantea una serie de nuevos retos e interrogantes sobre los recientes habitantes en el país.

Este número según datos del Ministerio de Relaciones Exteriores (2019) a través de Migración Colombia se incrementó para junio de 2019, ascendiendo a un millón cuatrocientos ocho mil cincuenta y cinco venezolanos que se localizan en Colombia, de los cuales, casi el $52,72 \%$ (742.390) se encuentran como regulares (portador de cédula de extranjería, pasaporte dentro del tiempo establecido y portador del permiso especial de permanencia), el resto son considerados irregulares. De ellos, un total de 197.428 son menores de 18 años, es decir, menores de edad para cursar estudios en básica y bachillerato, encontrándose la cantidad de 185.733 personas en el departamento del Norte de Santander y que son parte de un conglomerado de individuos donde la desigualdad define un fenómeno que resalta la brecha en la repartición del ingreso disponible 
entre los diferentes hogares o individuos en un espacio determinado (Lozano, 2019) ,

Para el año 2020, según cifras de Child Resilience Alliance-UNICEF (2020) Colombia alberca cerca de 1.7 millones de ciudadanos venezolanos que buscan oportunidades, en medio de la más grave crisis social, política y económica de la historia de su país, argumentando que en este flujo migratorio existen docentes, padres, representantes, niños, niñas y adolescentes venezolanos que impactan el sistema educativo colombiano, ya que todos inmigrantes en edad escolar pueden ir al colegio y no necesitan ningún tipo de documento que acredite su situación migratoria en el país.

No obstante, Baena \& Cardona (2021) al referirse al acceso a la educación y fenómeno migratorio venezolano, sostienen que se evidencia una escasez de integración de la migración a las políticas públicas locales, ya que restringe el acceso a la educación, ya sea por razones económicas o por necesidades de infraestructura; se desconoce la realidad misma del fenómeno. Por ello, es importante estudiar las relaciones sociales vividas por los padres y de los estudiantes inmigrantes.

De acuerdo con Carrillo (2005) tanto padres como sus hijos son afectados por el proceso migratorio y traen consigo diversas representaciones y constructos marcados por la perspectiva desde la que se aborda. En este sentido, es necesario tener claro el punto de partida, el referente que justifica todas las acciones pedagógicas, este concepto va más allá de una(s) u otra(s) práctica(s) de enseñanza y aprendizaje que engloba toda la acción dentro del contexto escolar, y lo eleva a algo más amplio, que involucra diversos aspectos de la vida del sujeto (estudiantes inmigrantes) y su interacción con el mundo.

Por otro lado, existen estudios sobre el tema en Colombia. Citemos en particular (Isaza, 2012) en relación con los imaginarios migratorios, algunos temas tratados son las percepciones de los migrantes, las figuraciones de la vida en el exterior y las costumbres de los parientes de los emigrados que permanecen en Colombia. Además, Martínez y Ruiz (2018) abordaron las representaciones sociales construidas por los venezolanos con respecto a su condición de migrantes. Mientras que Peña y García (2018) analizaron las representaciones sociales de migrantes venezolanos acerca de su proceso de integración social. Entre tanto, Cortez (2020) trató de comprender el rol que ha desempeñado la escuela en la acogida de la infancia migrante venezolana, a partir de las narraciones de docentes y orientadores con el fin de afrontar el reto hacia la educación intercultural.

Por otro lado, Bautista y López (2020) transitan hacia el paisaje de la unidad para comprender los procesos de inclusión a través de las representaciones sociales de la migración en niños, niñas y adolescentes venezolanos. Al respecto, Isaza (2012.) afirmando que las representaciones o imaginarios en torno a la migración, se han estudiado en el contexto latinoamericano desde tres puntos de vista: (1) El punto de vista del migrante; (2) El punto de vista de la comunidad receptora y; (3) El punto de vista de la comunidad de origen.

Al comprender las representaciones sociales en los padres, es posible verificar el nivel de influencia de estas representaciones, ya que reflejan conocimientos dentro y fuera del ámbito escolar, considerando su capacidad de adaptación e integración, de tal manera, que la población venezolana se ha visto obligada a buscar nuevas oportunidades en la frontera Colombo-venezolana, sin importar la precariedad laboral que tienen que pasar para solventar la situación económica de sus familias y por consiguiente, lo educativo de sus hijos, dado que las representaciones sociales circulan, se cruzan y cristalizan continuamente, a través 
de palabras, gestos, encuentros, que, ante la comunicación compartida entre los sujetos, se vuelven casi tangibles en el mundo cotidiano (Moscovici, 2007). Por tanto, la relevancia de este estudio radica en comprender los imaginarios y representaciones sociales de padres/representantes inmigrantes radicados en la Ciudad de Cúcuta, Norte de Santander, Colombia, sobre el fenómeno de migración y educación.

\subsection{REPRESENTACIONES SOCIALES E IMAGINARIOS EN EL FENÓMENO MIGRATORIO Y EDUCACIÓN}

El caso venezolano refleja migrantes a gran escala Sur-Sur del continente americano, ya que tienen más posibilidades por ser indocumentados $y$, por lo tanto, de ser trabajadores con contrato temporal; a menudo se les excluye de los servicios sanitarios, educativos y sociales; y son vulnerables en varios aspectos en la dignidad humana. De acuerdo con Pinto, Baracaldo y Aliaga (2018) La Ruta de Atención para Migrantes Venezolanos en Colombia ha reglamentado el acceso a la educación para estudiantes migrantes.

De allí, que lo único que debe hacer el padre de familia para el acceso a la educación preescolar, básica y media es que el estudiante se acerque a la institución educativa o a la secretaría de educación donde puede solicitar un cupo. Aunque, algunos establecimientos exigen tener estatus de regularidad a los migrantes para acceder a la educación. Por otro lado, Rincón, Contreras y Contreras (2021) haciendo referencia a los estudiantes en este contexto migratorio mencionan que estos necesitan de un psico orientador y de sus padres para la adaptación escolar.

García-Yepes (2017) afirma que no se puede confundir la integración con la adaptación, ya que ellas influyen sobre la construcción de las ideologías y las actitudes. Además, plantean que es necesario desarrollar procesos más inclusivos en el ámbito académico que impliquen a todos los actores escolares, ya que existe una percepción sesgada y estereotipada hacia la población migrante, pues en cada imaginario social existe una representación(Segovia \& Rendón, 2020).

Respecto a los términos $\square$ imaginario $\square$ y $\square$ representación social $\square$ de acuerdo con Isaza (2012.), se han empleado con el fin de aludir a construcciones sociales, significados que los sujetos estatuyen. De igual manera, argumenta que los imaginarios migratorios, como subconjunto de los imaginarios sociales, comparten las consideraciones teóricas precedentes según la corriente o autor, escogido como sustento teórico del estudio y que lo imaginario confluye con la noción de representación colectiva.

Es necesario acotar que, la representación colectiva fue dada a conocer por Durkheim (1898). Este, fue el primero en identificar objetos sociales, imaginarios o reales, como un evento, material psíquico o social, un fenómeno, una idea, una teoría, como producciones mentales sociales de la idea colectiva. Para Durkheim (ob. cit.) Las representaciones son su tejido surgen de las relaciones que se establecen entre los individuos o entre los grupos secundarios que se insertan entre el individuo y la sociedad en su conjunto. De igual modo, es importante mencionar que Serge Moscovici captó el lado procesual y social de las representaciones colectiva de Durkheim para el estudio y desarrollo de la Teoría de las Representaciones Sociales publicado en 1961 (Moscovici, 1979)

Atendiendo a la complejidad de los conceptos y comparando estas evidencias, entre lo imaginario y las representaciones sociales, el primero, se relaciona con la manera en que el/los sujeto(s) conciben lo real y la dimensión social que posee esa concepción. La dicotomía ficticia/real, doxa/episteme pierde entonces 
importancia frente a una ontología de lo social (Isaza, 2012). Entonces, socialmente se forma un conjunto de representaciones de una sociedad. El segundo, las representaciones sociales tiene como función la elaboración de los comportamientos y la comunicación entre los individuos y es definida por Moscovici como: :

...un corpus organizado de
conocimientos y una de las
actividades psíquicas gracias a
las cuales los hombres hacen
inteligible la realidad física y social,
se integran en un grupo o en una
relación cotidiana de intercambios,
liberan los poderes de su
imaginación (Moscovici, 1979:17-
18).

De allí que las representaciones sociales se producen intelectual y socialmente, además, se vinculan a los valores y la historia del grupo, dado que el sujeto y el objeto no son esencialmente diferentes, de este modo, todas las interacciones humanas que surjan entre dos individuos o entre grupos, presupone una representación (Moscovici, 2007), de allí, que todos los elementos nuevos se agregan y se sintetizan en él y se codifican, además, el autor precitado argumenta que cuando una persona $\mathrm{u}$ objeto no se ajusta exactamente al modelo, se obliga a asumir una determinada forma, a entrar en una determinada categoría, de hecho, a volverse idéntico a los demás, de lo contrario no se entiende ni se decodifica.

Retomando lo concerniente a los imaginarios, Desde el punto de vista de Girola (2020), los imaginarios sociales siempre hay que hablarlo en plural, debido que en cada sociedad y momento histórico, coexisten una multiplicidad de imaginarios, que son construcciones sociales simbólicas, esquemas e ideas acerca de la realidad. Son representaciones de interpretación yalmismotiempo, motores paralaacción. Porello, señala que los imaginarios y representaciones sociales no deben ser conceptos mutuamente excluyentes. Son nociones complementarias, ya que es sólo a través de las representaciones (y de los comportamientos) como podemos llegar a descubrir los imaginarios subyacentes.

Entiendo, que los inmigrantes pueden formar un sentido de pertenencia al destino (Maldonado, Martínez \& Martínez, 2018), su acceso a la educación también proporciona a las personas migrantes un canal de integración social, pero no antes de que los inmigrantes hagan una reacomodación de la identidad personal y cultural. A nuestro entender, la integración promueve el encuentro y el diálogo de los distintos grupos sociales que conviven en la escuela y; las escuelas son un reflejo de la sociedad y a través de ellas igualmente se puede observar, comprender e interpretar, las experiencias relacionadas con la migración en la educación y sus representaciones

Las representaciones sociales, son producto de la comunicación interindividual. Su función principal es "hacer algo inusual o desconocido en sí mismo familiar" (Moscovici, ob. cit, p. 38). Además, el carácter social de las representaciones procede del hecho de que los códigos de comunicación son proporcionados del trasfondo cultural común de un contexto dado, estructurado por principios, valores e ideologías. Es decir, las representaciones sociales son una colección organizada de información, opiniones, actitudes y creencias sobre un objeto dado (Abric, 2003). De hecho, este último autor postula que, de la producción social, [están] fuertemente marcadas por valores correspondientes al sistema socio ideológico y a la historia del grupo que los transmite para lo cual constituye un elemento esencial de su visión del mundo, pues concentran retratos con un sin número de significados; sistemas interpretativos que proporcionan sentido a lo impensado. 
Las representaciones sociales se construyen, evolucionan y transforman dentro de los grupos sociales y sobre el papel de estas construcciones en las relaciones de estos grupos con el objeto de sus representaciones. Al respecto, Materán señala que:

Esa representación social
implica la transformación o
construcción, porque en el proceso
de representación, los sujetos
interpretan la realidad y esa
interpretación está mediada por
los valores, religión, necesidades,
roles sociales, y otros aspectos
socioculturales. Al interpretar esa
realidad, no se copia sino que
se transforma y se construye.
Por tanto, la representación está
asociada al lenguaje y a las
prácticas sociales de determinado
grupo cultural. (Materán, 2008,
p.243-244).

De allí que, el ámbito educativo aparece como un campo privilegiado para ver cómo se complementa lo imaginario con las representaciones de los inmigrantes y sus familiares (padres y representantes), ya que lo imaginario emerge como el contexto sociohistórico de las representaciones sociales. Parafraseando a Moliner (2008) de esta asociación surge un nuevo significado que está directamente ligado al objeto de representación, es decir, los migrantes en la educación de sus hijos y de ellos mismos se autodescubren como miembros del país receptor, puesto que se implican e incorporan de sus significaciones sociales "imaginarios", y a su vez, se aprecian y perciben dentro de la misma; es allí de acuerdo con (Velázquez, 2013) donde las representaciones sociales e imaginarios se tocan.
Este campo de activación del proceso de representación es una noción importante para comprender el estudio de las construcciones mentales colectivas. Abric y Guimelli (1998) lo abordan bajo el de $\square$ contexto $\square$, por lo tanto, esta teoría se utilizará para describir y analizar los elementos cognitivos que sirven en sus concepciones de la educación en los inmigrantes y su comportamiento en la educación. A nuestro entender, los sistemas cognitivos que tienen una lógica y un lenguaje particulares, una estructura de implicación que se relaciona tanto con los valores como con los conceptos, Por lo tanto, no solo se ven $\square$ opiniones sobre $\square$, $\square$ imágenes de $\square$ o $\square$ actitudes hacia $\square$, sino $\square$ teorías $\square$, $\square$ ciencias $\square$ sui generis, destinadas al descubrimiento de la realidad y su ordenación.

De este modo, la representación funciona como un sistema de interpretación de la realidad que rige las relaciones de los individuos con su entorno físico y social, así como de lo imaginario entre el fenómeno migratorio y la educación, por tanto, determina sus comportamientos y prácticas. La representación es una guía para la acción y las relaciones sociales. Es un sistema de precodificación de la realidad, porque determina un conjunto de expectativas (Abric, 2001: 13) y de cómo se imagina la vida al comienzo del proyecto migratorio y la vida cotidiana (Isaza, 2012), ya que el imaginario en opinión de Velázquez (2013) son matrices de sentido, producción de significaciones y representaciones hacia algo, es decir, cómo debería ser organizado, pensado, utilizado o apropiado tras la institucionalización de dichas significaciones, a ser parte o partícipe de dicha realidad migratoria en el contexto educativo colombiano.

\section{METODOLOGÍA}

La presente investigación se desarrolló bajo el enfoque cualitativo, con el fin de encarar el mundo de la interioridad de los sujetos sociales y 
de las relaciones que establecen con el contexto y con otros actores sociales.

De acuerdo con Galeano (2004) se asume el conocimiento como un producto social y su proceso de producción colectiva influenciado por los significados de los sujetos que los construyen mediante del cual se obtiene dicho conocimiento de la realidad humana.

De este modo, el investigador interactúa con los sujetos y con los datos, para encontrar el sentido que los sujetos atribuyen a las experiencias humanas en los contextos sociales y culturales en los que están insertos (Taylor y Bogdan, 2000) a su vez, esta indagación, se fundamenta en un enfoque fenomenológico para entender los fenómenos sociales desde la propia perspectiva del actor. La realidad que importa es lo que las personas perciben como importante, de esas realidades vivenciales, que son determinantes para la comprensión de la vida de cada persona (Martínez 2004), útil para abordar lo imaginario y representaciones sociales de migrantes en la Ciudad de Cúcuta sobre la migración y educación.

El diseño de la investigación es abierto y flexible, de carácter descriptivo e interpretativo. La selección de los informantes clave se realizará tomando como base los planteamientos de Martínez (2007, p.54) en relación con una muestra de tipo intencional en la cual $\square$ se eligen una serie de criterios que se consideran necesarios o muy convenientes para tener una unidad de análisis con las mayores ventajas para los fines que persigue la investigación $\square$

De ahí, que los sujetos de investigación son cinco migrantes venezolanos, dos hombres y tres mujeres, con edades comprendidas entre los 25 y 40 años que se encuentran en la Ciudad de Cúcuta, facilitando así la comprensión de su imaginario y la construcción de sus representaciones a partir de ambas perspectivas. Para recoger la información se combinarán métodos narrativos e historia de vida pues es algo vivido y su significado. También, se emplean técnicas como la entrevista a profundidad, la cual permite analizar a través del diálogo las diferentes perspectivas, conocimientos, ideas y las actitudes de los entrevistados frente al contexto de venezolanos desde la construcción de sus representaciones sociales con respecto a la migración y la educación.

Sobre las bases epistémicas y metodológicas asociadas a la fenomenología se tomaron los principales puntos procedimentales propuesto por Martínez (2004) para el análisis e interpretación y proceso de comprensión. Por ello, los datos fueron examinados sistemáticamente para determinar partes y descubrir las relaciones entre las mismas y las relaciones con el todo, es decir, una vez culminado el proceso de recolección de información, transcripción, reducción y descripción protocolar y materia base sobre el cual se centra el estudio, así como las temas centrales que domina cada unidad temática, se inició el proceso de construcción de categorías de análisis a partir de la integración de todas las estructuras globales, confrontando estos relatos con la teoría presente en este trabajo y formulada en el apartado del marco teórico que sirvió de base para esta investigación.

A partir del anterior proceso surgió el siguiente listado de categorías y subcategorías que responden a los intereses temáticos del presente proceso (ver tabla 1 ). 
Tabla 1. Sistema de Categorías y subcategoría

\begin{tabular}{|l|l|}
\hline Categoría & Subcategoría \\
\hline Imaginario de los padres y representantes & $\begin{array}{l}1.1 \text { Los padres y representantes antes la migración } \\
1.2 \text { Percepción hacia la educación por parte de los } \\
\text { padres y representantes } \\
1.3 \begin{array}{l}\text { Los padres y representantes ante las políticas } \\
\text { de migración y la educación }\end{array}\end{array}$ \\
\hline $\begin{array}{l}\text { Representaciones sociales de los padres y y y } \\
\text { representantes }\end{array}$ & $\begin{array}{l}1.4 \text { Acceso, adaptación e integración a la } \\
\text { educación (al contexto educativo) } \\
\text { El padre y representante migrante ante el } \\
\text { contexto educativo }\end{array}$ \\
\hline
\end{tabular}

\section{3.- INTERPRETACIÓN DE LA INFORMACIÓN Y DISCUSIÓN}

\subsection{Sub Categoría: Los padres y} representantes antes la migración

La búsqueda de una vida mejor siempre ha sido una de las principales motivaciones de los inmigrantes, y esto también se ha convertido en el principal motivo de inmigración de venezolanos. Esta realidad, son esquemas de interpretación a la realidad del desequilibrio político y desarrollo económico del país cómo causa fundamental de dicha migración. Estas acciones de acuerdo con la visión de los informantes son ideas que muestran las razones para la inmigración y sus implicaciones en su(s) representado(s). Se destaca principalmente, los beneficios de la inmigración. En pocas palabras, tres factores más importantes para la inmigración son: la educación de los hijos, garantizar lo socioeconómico y prepararse para el futuro.

Al respecto, los sujetos S1 y S3 manifiestan:

Nunca pensé en salir de mi país, soy una madre que tenía una carrera y procuraba una vida para mis hijos, aunque entiendo que no hay un país perfecto en este mundo para vivir. Solo el buen bienestar, darle lo mejor a mis pequeños me incentivó a emigrar. [S1]

Salir de Venezuela en las condiciones de vida actual aporta grandes beneficios a mi familia, incluso a ellos mismos. Me preocupa la seguridad, la alimentación, la salud y la educación de María (hija). Mi esposo y yo hemos elegido bajo nuestras propias necesidades y condiciones reales hacer vida en Cúcuta y no continuar en Mérida, de lo contrario es fácil dar la vuelta. [S3]

de verdad, al venirme a Cúcuta sólo me preocupaba la darle algo mejor a mis hijos. Mis amigos me dijeron que estar ilegalmente es sinónimo de baja remuneración y que mis hijos no podrían estudiar porque la educación es costosa. [S1]

De igual forma, se puede observar que los informantes 2 y 5 revelan que existen estructuras sociales propia de la educación, lo cual imaginan en su participación dentro la escuela. Este padre y esta madre consideran lo siguiente: 
Soy un pequeño empresario que vino a probar suerte a Colombia, La educación aquí es costosa. Quien tenga más o mayores posibilidades económicas tendrá mayores decisiones relacionadas con la educación de sus hijos. La familia es esencial para el colegio. [S2]

La migración que imaginamos no es una aventura, es duro salir del país y del confort, más que una vida digna es esperanza, no importa los precios de la vivienda y sus servicios, pero importa la educación de mi hijo. [S5].

Pareciera que el acceso a la educación en el proyecto de migración a menudo se vuelve más fuerte para unos que para otros. Para Baenas y Cardona (2021, p.330) la población venezolana en Colombia se encuentra en una situación vulnerable, irregular y marginada $\square$ lo cual aumenta el riesgo de exclusión del sistema educativo. Estas desigualdades sociales requieren ser identificadas para resolver el acceso $y$, posteriormente, el diseño de los programas académicos de acuerdo con las variaciones culturales que trae la migración... $\square$.

En ese sentido, si se quiere alcanzar el cuarto Objetivo de Desarrollo Sostenible (ODS) (educación de calidad y oportunidades de aprendizaje permanente para todos), se debe considerar en la educación colombiana que todos los indicadores son inseparables, desde cualquier nivel educativo y de esa manera alcanzar la meta 4.5 de los ODS para eliminar las desigualdades y garantizar la igualdad de acceso a todos los niveles de educación a niños en situaciones vulnerables.

\subsection{Subcategoría: Percepción hacia la educación por parte de los padres y representantes.}

Comprender los entornos hogareños de los estudiantes migrantes es importante porque pueden estar relacionados con la información de cada caso que se debe parcialmente a la propia actividad del sujeto y su creencia sobre lo educativo en su conjunto, lo cual ayuda a interpretar las relaciones entre migración y educación de los individuos antes y después de la partida del país de origen. Se distingue cuando los padres y representantes dicen:

Todo en la vida es educación y cada padre y madre tiene la responsabilidad de la educación de los hijos y participar activamente en la escuela, todos tenemos el derecho a estudiar, para mí la educación es derecho humano, pero como padre tengo muchas expectativas para el futuro de mis hijos. [S4].

La educación en la escuela debe desarrollar en sus estudiantes habilidades para ayudar afrontar los cambios [S1]

De igual modo, se enfatiza sobre la educación como herramienta fundamental de la sociedad. Para los informantes:

La educación es la herramienta vital de superación personal y es elemento esencial para el progreso. Es primordial que la educación sea integral, con valores y de calidad que brinde la oportunidad de integrarse a la sociedad independientemente que uno sea inmigrante o no. [S2].

Se requiere que la educación sea efectiva, adecuada y en función de los estudiantes y la sociedad. [S3]

En correspondencia con lo mencionado, los padres y representantes valoran positivamente la educación y todo lo que ella encierra, dado que ésta (la educación) como hecho social alberga una relación en la dinámica de inclusión social y adaptación de los migrantes, esta 
inclusión y adaptación está presente en los diversos procesos vinculantes que obedecen a actividades receptoras que son resaltantes del mundo real que permite interpretar el entorno de las experiencias vividas de quien las experimenta. Lo cual coincide con el argumento de Cortez (2020), quien sostiene que la escuela es un espacio de inclusión social que requiere cambios bidireccionales que pasa por una adaptación que le permite reducir brechas de desigualdades en la escuela, sin negar la escuela como espacio de adaptación.

Esta realidad educativa en la migración se caracteriza por la intersubjetividad de padres y representantes que es influido por lo que piensan y de la población receptora, es decir, la influencia del contexto (Abric \& Guimelli, 1998), pues es un proceso pedagógico y social, la inclusión permite el intercambio de valores, ritos sociales, hábitos de la cultura colombiana con la venezolana y que a su vez se ve permeada por el regionalismo medios de comunicación en muchos de sus procesos (Bautista y López, 2020)

\subsection{Subcategoría: Los padres y representantes ante las políticas de migración y la educación}

La educación y la migración están estrechamente relacionadas, estos dos temas se conectan tanto a nivel macro como micro, en cuanto a las políticas migratorias, así como las políticas educativas. La informante expresa:

Al principio me sentí excluida aunque se qué como extranjera debo acatar las políticas de ingreso al colegio. Para tramitar el cupo primero fui al colegio y luego a la Secretaría de Educación y desde allí dieron la autorización. [S4]

Estas políticas tienen como estrategias primeramente la inclusión y también que las personas que entran a Colombia y dejen de estar de manera irregular. Lo que concuerda con la afirmación de Pinto, Baracaldo y Aliaga (2018, p.207) quienes mencionan que en las políticas públicas en educación $\square$ no se podría negar el acceso a los servicios públicos básicos por falta de requerimientos legales... No obstante, el Gobierno hará seguimiento a estas familias/ personas que ingresan a Colombia bajo la irregularidad, para que se actualicen... $\square$

Entré de manera ilegal a Colombia en el 2017, mis hijos están actualmente estudiando en un colegio público, pero en un principio no fueron aceptados, luego diligencie su acceso al colegio a través de la Secretaría de Educación. Tengo mis documentaciones en regla y visa de inmigrante y aquí vivimos feliz. [S1]

la política de bienestar social educativa están bien estatuidas y se llevan a cabo... [S5]

En esta dirección, se destaca que el acceso a la educación de migrantes venezolanos muchas veces no es posible pero está $\square$ ligado al interés de conocer y acceder ...y al interés personal $\square$ (Peña y García, 2020, p.93). En ese sentido, se entreteje y concurren las políticas de migración y educación con lo ideológico del propio individuo; pues, perciben los momentos reales, efectos de sus pensamientos y sucesos de las representaciones más allá del proceso de esquemas y eventos migratorios. Al respecto, el padre señala que :

La escuela para mis hijos no ha sido fácil, primero la educación en Venezuela es menos exigente y segundo, hemos brincado de un lugar para otro y se percibe el rechazo hacia nosotros, ...no dejó de luchar y por eso cada día me involucro más en el aspecto educativo de ellos porque han presentado falencias en el grado que cursan y el nivel de la educación básica. Ha sido difícil la adaptación y aprender 
nuevas costumbres, primero estuve en Bogotá, luego en Cali y desde hace dos años vivo en Cúcuta, incluso me ha tocado hacer cursos de actualización mediante el SENA para obtener certificaciones y ampliar mi hoja de vida. [S2]

En este transitar, la proyección que los padres y representantes hacen de lo académico para sus hijos un hilo conductor de las complejidades de la migración entre la edad del estudiante, la dependencia hacia sus padres/representantes y la búsqueda de información sobre la Educación (Peña y García, ob. Cit.). Por tanto, es un espacio de confluencias entre los sujetos migrantes y sus pensamientos, quienes con su acción construyen día tras día con ciertos valores, normas y leyes, características sociales, culturales, económicas y una cultura educativa que demanda una participación en el colectivo y sus implicaciones con su representado.

\subsection{Categoría: Imaginario de los padres y representantes.}

Tomando en cuenta el imaginarios de los padres y representante ante la migración, se comprendió que estos sienten fe, confianza y necesidades, se adaptan a las nuevas condiciones reales, demuestran interés hacia el bienestar y la educación de sus representados, lo cual trae como consecuencia una construcción del sujeto y una clara vinculación con la imagen del individuo y el imaginario social que forma un pensamiento a partir de las experiencias con las cuales crea exégesis sociales intersubjetivas que no son expeditamente detectables, ya que $\square$ depende en gran medida del perfil de los entrevistados $\square$ y de $\square$ las vivencias e ideas que se tienen antes de emprender el viaje, imaginarios sobre el país de destino... $\square$. (Izasa, 2012, p.191), con respecto a las más variadas dimensiones y objetos del imaginario migratorio de cada padre y representante de los estudiantes en las nuevas realidades y contextos socioeducativos colombianos.
Otra subcategoría que destaca con claridad la percepción hacia la educación, lo cual hace representación notablemente en el imaginario familia-escuela para estimular el beneficio hacia la educación y su representado, aunque en algunos escenarios educativos se evidencian rechazo y xenofobia. En este sentido se comprende, que los padres y representantes migrantes crean conciencia y apreciación de su realidad como actor social, es separar con qué llegan estos (inmigrantes), de cómo se adaptan, asimilan después de la inmigración y el asentamiento, por ello, existe una representación de ese imaginario social (Segovia \& Rendón, 2020). pues, los padres y representantes se enfocan en dos temas principales para apoyar el proyecto migratorio: el éxito educativo así como la integración tanto social como económica

Lo anterior muestra, una construcción de un imaginario de los padres sobre la educación. Estos, piensan que la educación es inherente al individuo, impulsa el desarrollo particular, social, económico y cultural, de esta manera, se perciben como sujetos plenos de derecho en cuanto a la educación como un derecho universal inseparable al individuo, sin discriminación de sexo, raza o color. Lo cual, representa a los modos en que dichos padres y representantes imaginan su presencia en la sociedad. En otras palabras, describe las inclinaciones del pensamiento en cuanto a sus anhelos, afirmaciones, imágenes que los individuos conciben de su vida habitual e influye en su experiencia de manera objetiva e intersubjetiva al corresponder con su medio ambiente en la cotidianidad, ya que lo educativo, la adquisición de destrezas y conocimientos juegan un papel significativo en diversas etapas de la migración de una persona.

Desde un punto de vista de lo imaginario sociales, la posibilidad de una migración posterior puede afectar las valoraciones que hace el sujeto y decisiones educativas en el país de origen mucho antes de que se realice 
una migración, pero a su vez, pueden formar un sentido de pertenencia al destino como un canal de integración social (Maldonado, Martínez \& Martínez, 2018).

Acceder a la educación representa una oportunidad para que la familia ocupe su lugar en la sociedad de acogida. En esa dirección, se reconoce el imaginario en la relación con migración-educación y familia-escuela en la políticas públicas, pues, resulta esencial para que los individuos migrantes tengan una vida productiva y con sentido fuera de su país.

De hecho, se establece una relativa continuidad ideológica y de esquemas de valores sociales y actitudes básicas hacia las políticas educativas y migratorias. Por lo tanto, la educación en la migración dota tanto a los padres y representantes de un instrumento de valor universal de inclusión más allá del estado-nación en que el migrante puede apoyar sus razonamientos y hacen parte del diario vivir entre los vínculos familiares y sociales de los estudiantes.

\subsection{Subcategoría: Acceso, adaptación e integración a la educación}

Al preguntarle a los informantes respecto al acceso, adaptación y la integración a la educación en la Ciudad de Cúcuta, se evidenció que los padres y representantes tienen una percepción de que los niveles académicos son similares (el de Venezuela con el de Colombia). Por ello, la relación familia-escuela facilita la integración a la educación y por ende, a la sociedad. Al respecto, este padre consideran a los maestros como personas clave para su integración:

Mis pequeños están en tercero y cuarto de educación básica, nos estamos adaptando a este sistema educativo [S2].

Aquí, las maestras muestran a los niños una manera de trabajar de manera contextualizada algunas materias como las matemáticas. Por ejemplo, al mayor le enseñaron cómo prepararse, cómo organizarse. ( ) para las pruebas de matemática. [S4]

En conversaciones con la maestra, ella me dice que mi participación es fundamental ... [S5].

Por el contrario, la representante S1 dice tener no tan buena participación y confían en la educación que ellas imparten..

Mis hijos se han adaptado a la escuela muy rápidamente, sin embargo, yo pareciera que sigo operando en el sistema venezolano, continúo con ciertas costumbres pero la manera de asumir la educación en la escuela es de otra manera, trato de apegarme a la visión que tiene el colegio, a sus valores incluso, a las conversaciones con docentes. [S1].

Para ello, la adaptación y la integración se da una importancia al trabajo conjunto escuela-familia. Los objetivos migratorios familiares son exitosos siempre que se adapten y cuando la escuela promueva la integración. Lo cual coincide con el planteamiento de Rincón, Contreras y Contreras (2021) quienes recomiendan que el contexto migratorio colombiano necesita de un psicoorientador y de sus padres para la adaptación escolar porque la educación incide en expectativas, y creencias de los individuos.

Otro concepto emergente es el relacionado con la calidad de la educación, arroja a luz ciertas posiciones asumidas por los padres y representantes sobre la educación en la Ciudad de Cúcuta. En relación con lo anterior, los informantes expresaron:

...acá se habla mucho de calidad educativa y hacen mucha hincapié en desarrollar el talento de los estudiantes 
a largo plazo, la educación es buena.... Nos exigen que participemos en todas las actividades [S3]

...la calidad de la educación es unos criterios que se maneja en la escuela de mi hijo,...en Venezuela, los maestros de las instituciones públicas no hablan de calidad educativa. [S5]

El acceso a una educación de calidad se acompaña de la adaptación y la integración, Lo cual coincide con Pinto, Baracaldo y Aliaga (2018) quienes afirman que el Gobierno colombiano ha adelantado estrategias aplicadas a la necesidad de integración de los migrantes venezolanos, por ello, argumentan que la integración viene dada por el acceso; la focalización que abordar la situación educativa de los grupos de migrantes; las nuevas oportunidades para la integración y; una educación intercultural para todos que refleje la diversidad en el currículo.

\subsection{Subcategoría: El padre y representante migrante ante el contexto educativo}

Los padres y representantes inmigrantes conciben el contexto educativo como una oportunidad beneficiosa a sus anhelos pedagógicos de sus hijos y sabedores de su participación en el mismo. Como expone esta mujer venezolana, madre de dos hijos:... independientemente de lo forzado que es $\mathrm{mi}$ trabajo, sé que ellos (hijos) necesitan cien por ciento de mi, muchas veces no es falta de interés en conocer, saber o preguntar como van ellos en la escuela pero los ayudo con sus tareas escolar cuando llego de trabajar. (S1).

Desde esta perspectiva, emerge que la madre descuida asuntos del contexto educativo para responder a la jornada laboral poniendo sobre el tapete un asunto de vulnerabilidad de los estudiantes migrantes. Por otro lado, la otra madre [S3] considera que la educación colombiana presenta ventajas, además, la cataloga que es de calidad y requiere que los estudiantes construyan su conocimiento para tener un alto rendimiento escolar, pues piensa en el futuro académico de su representada. Las palabras de esta informante ilustran bien esta idea

Nosotros le decimos a María (hija) que tenga aspiraciones con sus estudios, que su colegio es de alta calidad educativa y requiere de su esfuerzo, la educación en Colombia es exigente y que apunte a lo alto hasta llegar a la universidad y que para ello necesita salir bien en la escuela. Le decimos que estudiar es una tradición en nuestra familia, mi esposo es profesional, yo soy profesional y nuestros padres son profesionales [ ]. (S3)

Estas interacciones corresponden a las experiencias que se efectúan en la institución educativa cuyos vínculos están asimilados de decisiones valorativas, que se manifiestan por medio de la interacción comunicativa, acciones, comportamientos e imaginarios. También existen construcciones de los padres que asumen la desventajas estructurales en la sociedad que lo acoge, ante el miedo de ser discriminado, los cuales parecerían tratar de evitarlo a toda costa.

El desafío se vuelve particularmente difícil de superar cuando los riesgos se acumulan y la discriminación al venezolano se agregan, sin embargo, trato de aayudar a mis hijos para que tenga tengan buenas notas y no lo se burlen de ellos por saber menos.[S1].

A pesar de que Mérida está relativamente cerca de la frontera y Venezuela y Colombia son dos naciones hermanas, sentimos que estamos en desventajas en la escuela. ... los esfuerzos vienen de nosotros como familia, no es fácil.[S3]. 
De allí, que la desventaja social y la migración están vinculadas a variables económicas. Sobre estas variables emergentes los informantes clave manifestaron que:

La crisis económica de Venezuela nos obligó a emigrar y ha traído como consecuencia efectos negativos, ya no ejerzo mi profesión y por ende bajos ingresos económicos. Independientemente de ser licenciada en administración aquí trabajo de domestica y no gano ni el sueldo mínimo pero trato de que a mis hijos no les falte nada y que vayan pulcro a la escuela ...y cumplan con sus deberes.[S1].

Creo que la desigualdad en los ingresos familiares definen la posición en la sociedad y la escuela no escapa de eso. [S2]

El primer año en Bucaramanga nos preocupaba mucho los pocos ingresos, vivimos de vender café y tortas en la calle, tuvimos pocas oportunidades de trabajo para sostener la casa, los servicios, la educación. Luego que llegamos a Cúcuta mi pareja encontró trabajo y yo emprendí en un negocio con ayuda de un hermano, las cosas han ido mejorando.[S3]

Se pueden observar varios elementos. Primero, una desigualdad por el nivel socioeconómico heterogéneo, expresado por la profesión de los padre (licenciada, comerciante) seguido de un desplazamiento de mano de obra y mano de obra barata así como la informalidad laboral, que resalta la brecha económicas entre los diferentes hogares o individuos (Lozano, 2019) ,lo cual pudieran presentar actitudes tanto positivas como negativas en relación entre el fenómeno migratorio y las prerrogativas socioeconómicas en términos de integración tanto al mercado laboral como al contexto educativo.

\subsection{Categoría: Representaciones sociales de los padres y representantes.}

Las representaciones sociales de los padres y representantes en torno a los propósitos de la migración y educación, nos permite esclarecer algunos de los elementos que surgen de nuestras observaciones. Lo primero que llama la atención es que es indiscutible que la educación es una parte principal del proyecto migratorio de la familia, seguido que el acceso, la adaptación e integración está anclado por dos marcos de referencia, el sistema educativo venezolano como país de origen y el colombiano como país de acogida.

$\mathrm{Si}$ bien las razones que apoyan las representaciones sociales de los padres y representantes varían con respecto a la educación en cuanto al acceso, la adaptación e integración, está producciones son una imágenes que los sujetos informantes desarrollan en interacción con el contexto educativo de la Ciudad de Cúcuta, parece que las posiciones de los padres se estructuran, se transporta y ajusta en la sociedad de acogida. De este modo, en la nueva realidad construida constituyen un modo de conocimiento por los padres y representantes para captar elementos en el sistema escolar de acogida que incluso ya han sido construidos en la sociedad de origen.

A pesar de que los sujetos informantes identificaron de forma casi similar los niveles educativos de ambos países. La participación, familia-escuela y el énfasis que se hace sobre la calidad educativa, sufren ciertas transformaciones al estar en el nuevo contexto, es lo que Segovia \& Rendón (2020), llaman que en cada imaginario existe una representación social, lo cual se debe los valores y la historia de los grupos sociales (Moscovici, 1979; 2007) que se vinculan y se producen a las representaciones sociales que son familiares a la sociedad de origen, pues concuerda con el planteamiento de Moliner, (2008) que 
las representaciones sociales juegan, en la elaboración e interpretación de las imágenes, un papel comparable al de las narrativas que producen asociaciones figura / significado.

En este sentido se comprende, que el contexto educativo es un entorno rico que permite como los individuos construyen, evolucionan y se transforman sus representaciones en relación a la identidad institucional, generación de valores, interacciones y articulación de representaciones mentales. Los padres y representantes no sólo enfrentan los desafíos en relación con el proceso de proceso de recepción de otra cultura educativa y de asimilación al nuevo contexto sino que son orientados por el entorno escolar y por las normativa educativas en la ciudad de Cúcuta, como sociedad de acogida. Lo que está en concordancia con el planteamiento de Abric \& Guimelli (1998) y Abric (2003) quienes afirman que el contexto orienta los comportamientos de los sujetos.

La apropiación del contexto permitió a los informantes clave conocer más sobre el papel que juegan en la educación de sus hijos. Esta construcción social emerge en las relaciones mantenidas entre los padres y representantes y el objeto de sus representaciones, es decir, el contexto educativo. Es decir, el desarrollo de representaciones sociales en el contexto educativo permitirá a estos sujetos participar en el día a día en las actividades y labores de sus representados. Lo cual coincide con el planteamiento de Materán (2008) quien sostiene que las construcciones dentro de los grupos sociales evolucionan y transforman en las relaciones de estos grupos con el objeto de sus representaciones.

Evidentemente, no se trata solamente de reproducciones del contexto educativo sino de la acción de una imagen que los informantes desarrollan utilizando sus pensamientos. Esto permite por lo tanto, considerar el lugar que ocupan en el contexto de la migración y una posición real concebida en la sociedad de acogida, ya que presupone una representación (Moscovici, 2007). El hecho de estos esquemas sobre el contexto escolar y la migración son un desafío hacia el entorno escolar. En esa dirección, el tejido socioeducativo llevaría a los padres a posicionarse con más vigor en relación con la misión institucional, en sus valores e interacciones con los actores educativos, lo que coincide con Moscovici (2007) que son eventos que estan psicologicamente representados en cada uno de los participantes, por eso se infiere que el éxito educativo de los hijos es el objeto de una fuerte movilización para la mayoría de las familias inmigrantes.

\section{CONCLUSIONES}

En el presente artículo, se ha intentado investigar cómo la teoría de los imaginarios y representaciones sociales pueden interpretarse como una base para comprender en un contexto migratorio las diversas posiciones de los padres hacia la educación y hacia la escuela de sus hijos.

Las interpretaciones intersubjetivas subrayan que el imaginario de los padres y representantes venezolanos sobre el proyecto de migración hacia Colombia, nos sugieren que la experiencia migratoria no se presenta como una aspiración para el asentamiento en la Ciudad de Cúcuta. No obstante, el contexto escolar posee lugar estratégico en la integración de las familias recientemente inmigradas en la sociedad acogida.

En este contexto educativo, confluyen las políticas educativas y migratorias, escuela y familia para crear un ensamblaje para la adaptación y participación tanto de los estudiantes como de sus padres y representantes, aunque no siempre es así.

Los relatos de los informantes clave, exponen que los padres y representantes han experimentado 
choques culturales y educativos que pone en evidencia la irrupción de los imaginarios y construcciones sociales que traen del país de origen. Lo que abre un camino para reconocer el ajuste a nuevas representaciones sociales que inciden en la educación, y por ende, al acceso, adaptación y participación a las vividas y promovidas en el contexto de recepción de los padres y por consiguiente de sus representados.

Se concluye que los padres y representantes al integrarse activamente a la sociedad local, organiza y regula las experiencias y comportamiento asignando un valor al contexto educativo donde se desenvuelve su representado, y a su vez, fortalece la imagen de su propia conciencia objetiva de los criterios culturales, normativos y educativo de la representación y que es anclada al sistema de pensamiento preexistente.

\section{REFERENCIAS BIBLIOGRÁFICAS}

Abric, J.-C. (2001). A structural approach to social representations. In K. Deaux \& G. Philogène(Eds.), Representations of the Social (pp. 42-47). Oxford, UK, Malden, MA: Blackwell.

Abric, J.-C. (2003). La recherche du noyau central et de la zone muette des représentations sociales. In J.-C. Abric (Ed.), Méthodes $\mathrm{d} \square$ étude des représentations sociales (pp. 59-80). Ramonville Saint-Agne: Erès.

Abric, J.C. \& Guimelli, C. (1998). Représentations sociales et effets de contexte. Connexions. $\mathrm{N}^{\circ}$ spécial: Logiques sociales de la connaissance, 72 (2), 2338.
Aliaga, F., Baracaldo, V., Pinto, L., \& Gissi, N. (2018). Imaginarios de exclusión y amenaza en torno al inmigrante venezolano en Colombia. Temas y Debates, 36, 61-83. https://doi. org/10.35305/tyd.v0i36.415

Baena, N., \& Cardona, E. (2021). ¿Educación intercultural? A propósito del fenómeno migratorio venezolano en Medellín. Revista IUS, 15(47), 325-342. https:// doi.org/10.35487/rius.v15i47.2021.675

Bautista, D. y López, F. (2020). Transitando hacia el paisaje de la Unidad: Representaciones sociales de la migración en niños y niñas del Colegio Tibabuyes Universal I. E. D. Trabajo de grado. Magíster en Desarrollo Educativo y Social. Universidad Pedagógica Nacional. http://repository. pedagogica.edu.co/bitstream/ handle/20.500.12209/11501/TO-23751. pdf?isAllowed=y\&sequence $=1$

Carrillo, M. (2005). El espejo distante. Construcciones de la migración en los jóvenes hijos e hijas de emigrantes ecuatorianos. En Herrera, Carrillo y Torres [Editoras] (2005). La migración ecuatoriana. Transnacionalismo, redes e identidades. Pp. 361-170. FLASCO sede Ecuador: Imprefepp. http://www. flacsoandes.edu.ec/biblio/catalog/ resGet.php?resld=20299

Child Resilience Alliance-UNICEF (2020). Impacto del flujo migratorio de nna venezolanos en el sistema educativo colombiano -respuesta actual y recomendaciones https:// reliefweb.int/sites/reliefweb.int/files/ resources/75761.pdf 
Cortez, A. (2020). La escuela frente a la migración infantil venezolana: un reto hacia la educación intercultural. Pontificia Universidad Javeriana. https:// repository.javeriana.edu.co/bitstream/ handle/10554/52650/TESIS \% 20 FINAL\%202021.docx\%20\%281\%29. pdf?sequence=1\&isAllowed $=y$

Durkheim, E. (1898). "Représentations individuelles et représentations collectives". Revue de Métaphysique et de Morales, VI, pp 273-300. http:// classiques.uqac.ca/classiques/ Durkheim_emile/Socio_et_philo/ch_1_ representations/representations.html

García-Yepes, K. (2017). Procesos de integración social de inmigrantes en escuelas de Huelva, España: Diversidad cultural y retos educativos. Alteridad. Revista de Educación, vol. 12, núm. 2, pp. 188-200,. https://www.redalyc.org/ journal/4677/467751871005/html/

Galeano, M. (2004). Estrategias de investigación social cualitativa. El giro en la mirada. Medellín, Colombia: La carreta editores.

Girola, L. (2020). Imaginarios y representaciones sociales: Reflexiones conceptuales y una aproximación a los imaginarios contrapuestos. Revista de Investigacion Psicologica, 23, 112-131.

Isaza, M. (2012). Algunos imaginarios migratorios en Pereira y Dosquebradas. Imagonautas: revista Interdisciplinaria sobre imaginarios sociales, 2(1), 188209. https://dialnet.unirioja.es/descarga/ articulo/4781608.pdf
Lozano, D. A. (2019). El efecto de la desigualdad sobre el crecimiento departamental de Colombia. Obtenido de https://repository.eafit.edu.co/ bitstream/handle/10784/15188/ DionisioAndres_CastilloLozano_2019. pdf?sequence=2\&isAllowed $=y$

Martínez, M. (2004). Ciencia y arte en la metodología cualitativa. Editorial Trillas. S. A. de C. V.

Martínez, M. (2007). La investigación cualitativa etnográfica en educación. México: Trillas

Martínez, J. y Ruíz, S (2018). Representaciones sociales construidas por los venezolanos con respecto a su condición de migrantes en el municipio de Medellín, Colombia en el año 2018. Trabajo de grado presentado para optar al título de Psicólogo. Institución Universitaria de Envigado. http:// bibliotecadigital.iue.edu.co/jspui/ bitstream/20.500.12717/280/1/iue_ rep_pre_psi_mart\%C3\%ADnez_2019_ representaciones_sociales.pdf

Maldonado, C., Martínez, J. \& Martínez, R. (2018). Protección social y migración Una mirada desde las vulnerabilidades a lo largo del ciclo de la migración y de la vida de las personas. Comisión Económica para América Latina y el Caribe (CEPAL) - Naciones Unidas. Santiago https://repositorio.cepal. org/bitstream/handle/11362/44021/1/ S1800613_es.pdf 
Materán, A. (2008). Las representaciones sociales: un referente teórico para la investigación educativa. Geoenseñanza, 13 (2), 243-248. https://www.redalyc. org/articulo.oa?id=36021230010

Ministerio de Relaciones Exteriores (2019) Venezolanos en Colombia corte a 30 junio de 2019. https://www. migracioncolombia.gov.co/tramites-yservicios/tag/Radiograf\%C3\%8Da\%20 de\%20venezolanos

Moliner, P. (2008). Représentations sociales et iconographie. Représentations sociales et iconographie », Communication et organisation [En ligne], 34 , pp. 12-23, https://doi.org/10.4000/ communicationorganisation.547

Moscovici, S. (1979), El psicoanálisis, su imagen y su público, Buenos Aires, Huemul.

Moscovici, S. (2007) Representações sociais: investigações em psicologia social / Serge Moscovici: editado em inglês por Gerard Duveen: traduzido do inglês por PedrinhoA. Guareschi. -5a ed. Petrópolis, RJ: Vozes, https://www.academia. edu/25698906/MOSCOVICI_S_ Representa\%C3\%A7\%C3\%B5es_ Sociais

Organización Internacional para las Migraciones - OIM (2006). Derecho Internacional sobre Migración. Glosario sobre Migración, (7). Recuperado de http:// publications.iom.int/system/files/pdf/ iml_7_sp.pdf

Peña, C. y García, M. (2018) Las representaciones sociales de migrantes venezolanos acerca de su proceso de integración social en la ciudad de
Rionegro, Antioquia, 2018. Trabajo de grado presentado para optar al título de Psicólog. Universidad de Antioquia. https://bibliotecadigital. udea.edu.co/bitstream/10495/14027/1/ $\mathrm{Pe} \% \mathrm{C} 3 \% \mathrm{~B} 1$ a C a terine_2020_ RepresentacionesSocialesMigrantes. pdf

Pineda, E., y Ávila, K. (2019). Aproximaciones a la migración colombo-venezolana: Desigualdad, Prejuicio y Vulnerabilidad. Clivatge. Estudis $i$ testimonis sobre el conflicte $i$ el canvi socials, 7, Article 7. ttps://doi.org/10.1344/ CLIVATGE2019.7.3

Pinto, L. A., Baracaldo, P. \& Aliaga, F. A. (2019). La integración de los venezolanos en Colombia en los ámbitos de la salud y la educación. Espacio Abierto, 28(1), 199-223. https://www.redalyc.org/ jatsRepo/122/12262976013/html/index. html

Rincón, O., Contreras, R y Contreras, L. (2021). Estudiantes migrantes en la adaptación de la educación Colombiana. bol.redipe 10(9):526-43. https://revista.redipe.org/ index.php/1/article/view/1459

Segovia, P., \& Rendón, B. (2020). Estudiantes extranjeros/as en la representación de los docentes en una escuela de Santiago: Elementos para una educación intercultural. Polis. Revista Latinoamericana, 56, Article 56. https:// journals.openedition.org/polis/19337

Taylor, S y Bogdan, R. (2000). Introducción a los métodos cualitativos de investigación. España: Paidós. LIMUSA. 
Velázquez, O. (2013). Las representaciones sociales, los imaginarios sociales y urbanos: Ventanas conceptuales para el abordaje de lo urbano. Entelequia: revista interdisciplinar, №. 16, pp. 141155. https://dialnet.unirioja.es/servlet/ articulo?codigo $=4768111$ 